\title{
Methane dehydro-aromatization: potential of a Mo/MCM-22 catalyst and hydrogene selective membranes
}

\author{
Kaidi Gao ${ }^{1}$, Jianhua Yang ${ }^{2}$, Andreas Seidel-Morgenstern ${ }^{1,3}$, Christof Hamel ${ }^{1,4}$ \\ ${ }^{1}$ Otto von Guericke Universität Magdeburg, Universitätsplatz 2, D-39106, Magdeburg, Germany \\ ${ }^{2}$ Dalian University of Technology, Linggong Road 2, Ganjingzi Square, Dalian, 116024, China \\ ${ }^{3}$ Max Planck Institute for Dynamics of Complex Technical Systems, Sandtorstraße 1, 39106, Magdeburg, Germany \\ ${ }^{4}$ Anhalt University of Applied Sciences, Bernburger Str. 55, 06366 Köthen, Germany
}

\begin{abstract}
$\underline{\text { Abstract }}$
The exploitation of methane to produce aromates is already seen a long time as very attractive. Although investigated intensively, methane dehydro-aromatization (MDA) is far from being applied industrially. Unfortunately, MDA under non oxidative conditions is severely limited by thermodynamics. Further problems are a lack of sufficiently active and selective catalysts, low methane conversions connected with limited target product selectivities, as well as rapid catalyst deactivation.

Under non oxidative conditions Mo/MCM-22 was reported to be a promising catalyst. Three distinct operating regimes were observed in kinetic studies, namely an activation phase, a steady state production phase and a deactivation phase. Kinetic experiments were performed analyzing concentrations measured during the production phase to parametrize rate expressions and to identify trends regarding the selectivity-conversion behavior. The results allow estimating specific hydrogen production rates, which were used to evaluate the potential of exploiting hydrogen selective membranes within a membrane reactor of the extractor type. Such a removal would be beneficial to overcome the thermodynamic limitations. An attractive hydrogen selective membrane was characterized and its potential evaluated in simulation studies.
\end{abstract}

Keywords: Methane dehydro-aromatization, Mo/MCM-22, kinetic model, membrane reactor, kinetic compatibility 


\section{Introduction}

With the rapidly depleting of crude oil reserves of the world, opening new way to efficient use of methane as an alternative energy source are becoming promising, necessary and important ${ }^{[1]}$. Methane dehydro-aromatization (MDA) attracts considerable interests since the last decades for its potential in the conversion of methane to valuable long-chain chemicals especially aromatics ${ }^{[2]}$.

The desired overall reaction is

Methane dehydro-aromatization (MDA): $\left.\quad 6 \mathrm{CH}_{4} \rightleftharpoons \mathrm{C}_{6} \mathrm{H}_{6}+9 \mathrm{H}_{2}(1)\right)$

Comparing with other methane reaction pathways (Fischer-Tropsch reaction, partial oxidation, oxidative coupling, $\mathrm{CO}_{2}$ coupling etc.), there is no oxygen in a non oxidative MDA system which can avoid deep oxidation of methane and separation of $\mathrm{CO}_{x}$ from the products ${ }^{[3]}$. Furthermore, the sole reactant methane is abundant reserves ${ }^{[4]}$, and the desired product benzene is an essential industrial feedstock and the by-product hydrogen is a clean high efficient energy resource. Unfortunately, MDA is thermodynamically unfavorable under non-oxidative condition, which limits significantly the conversion of methane and yield of aromatics. Figure 1 illustrates the methane equilibrium conversion as a function of temperature.

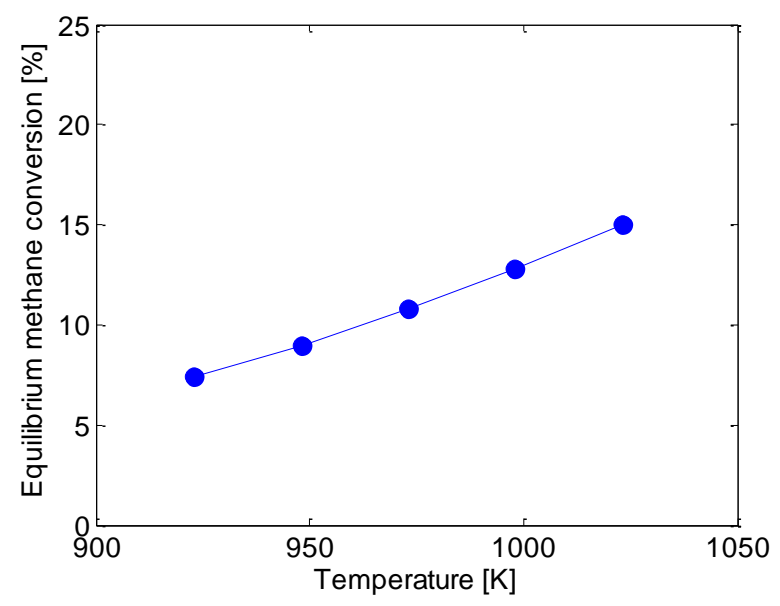

Figure 1: Calculated equilibrium methane conversion at different temperatures, Reaction (1) ${ }^{[5]}$.

\section{Catalyst and kinetic mechanism}

Intensive efforts have been devoted to develop catalysts with sufficient aromate selectivity. Promising results were achieved with Mo/ZSM-5 ${ }^{[5]}$, Mo/MCM- $49^{[6]}$ and Mo/MCM-22 $2^{[1,5 c, 7]}$ due to their two-dimensional pore structures and pore diameters close to the dynamic diameter of the benzene molecule $(\sim 6 \AA)$. However, rapid carbon depositions hamper industrialization of MDA.

The MDA was studied in this work on a bifunctional catalyst with molybdenum active sites and acid sites of a MCM-22 support as illustrated schematically in Figure 2. Methane reduces Mo sites to active $\mathrm{MoC}_{\mathrm{x}}{ }^{[8]}$ or $\mathrm{MoO}_{\mathrm{x}} \mathrm{C}_{\mathrm{y}}{ }^{[9]}$ species which convert methane to ethylene. Subsequently ethylene is oligomerized and aromatized on Brønsted acid sites of the zeolite to the desired product benzene ${ }^{[10]}$. In the initial phase I the active catalyst is formed connected with an increasing benzene production phase as depicted in Figure 3. 

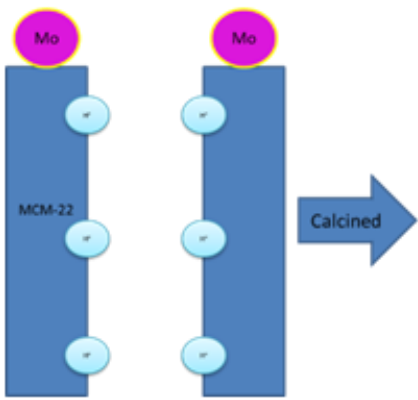

Figure 2: Illustration of onMo/MCM-22 under MDA reaction conditions
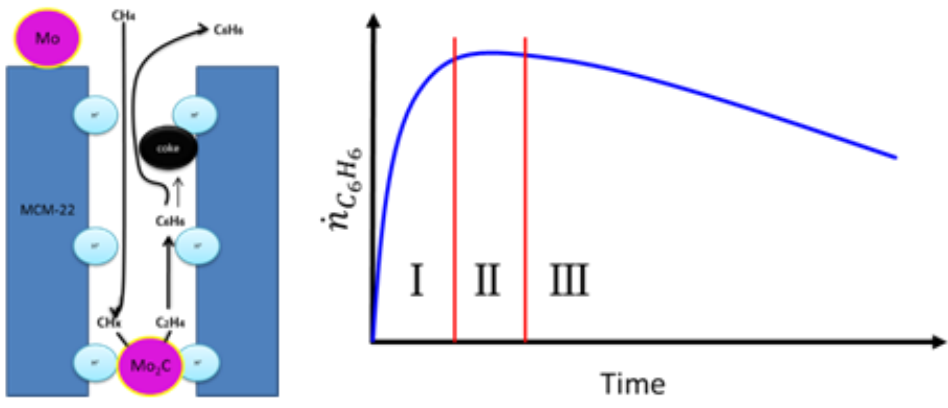

Figure 3: Benzene formation during 3 characteristic phases: activation (I), steady state (II) and deactivation as found for Mo/MCM-22 ${ }^{[1]}$

Highly dispersed molybdenum carbide on the surface of zeolite is considered as the active center of converting methane to ethylene, and ethylene migrates into the channel and is cyclized to benzene at the migrated Mo-acid sites, which is formed during catalyst calcination ${ }^{[10]}$. Benzene can disperse out as product or further react with activated $\mathrm{CH}_{\mathrm{x}}$ or ethylene to larger molecules, especially coke. Acid sites coated by coke lose their activity and coke may block the zeolite channel prohibiting transportation in between, which induce the deactivation of catalyst. Thus, after a pseudo steady state (II) and deactivation state occurs (III) (Figure 3) which was also reported by ${ }^{[11]}$.

Since 1993 Wang et al. ${ }^{[12]}$ firstly reported dehydrogenation and aromatization of methane for non-oxidizing conditions, MDA attracted plenty of attentions especially in the aspect of catalyst selection and reaction mechanism. Many catalysts based on metal ions dispersed on various supports have been investigated. Among different metals ${ }^{[5 \mathrm{i}, 13]}$, Mo based catalyst exhibit the best performance in the conversion of methane to aromatics. W, Re and Co-Ga also show some activities, while other metal ions have very low activity for MDA. Different zeolites supports loaded with Mo have also been studied ${ }^{[14]}$, HZSM-5 is the first found suitable support for high activity Mo-based catalysts for MDA, but catalysts based on HMCM-22 and HMCM-49 exhibit similar MDA activity, higher selectivity to benzene, and a better tolerance of carbonaceous deposits. Thus, in this work for an experimental and model based investigation of the methane dehydro-aromatization Mo/MCM-22 was chosen as catalyst.

\section{Catalyst preparation and characterization}

The MCM-22 support used in the work was synthesized using hexamethyleneimine (HMI) as a structure direction agent as reported by $\mathrm{Chu}{ }^{[7 \mathrm{c}]}$. The synthesized support was characterized by transmission electron microscopy (TEM) and scanning electron micrograph (SEM, KYKY-2800B). Figure 4 illustrates the SEM and TEM images of MCM-22. The SEM image (4a) shows irregular shaped aggregates morphology, which is assembled by the intergrowth of many small flaky crystals. The TEM image (4b) proves the MCM-22 and confirms it is hierarchical. Lattice fringes can be observed in the high resolution TEM image of the part marked by the red circle, which reveals that this zeolite possesses high crystallinity. Pore size distribution was obtained by BJH method. The existence of mesopores in MCM-22 is proved, which gives the average pore diameter of $4 \mathrm{~nm}$ (conventional MCM-22 is $1.93 \mathrm{~nm}^{[7 \mathrm{c}, 15]}$ ). Mo was loaded into MCM-22 by wet impregnation. The loading of Mo amounts 5wt\% (EDXRF). 
a)

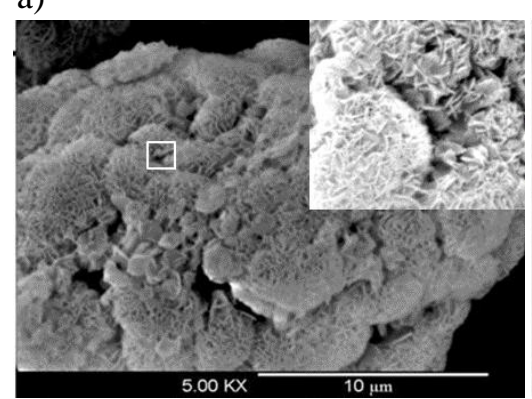

b)

Figure 4: a) SEM and b) TEM images of the zeolite MCM-22

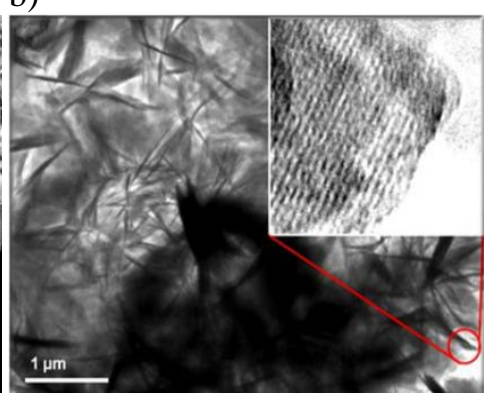

\section{Experimental setup}

The MDA experiments were performed in a typical laboratory fixed-bed reactor (FBR, Figure 5). The fixed-bed reactor applied was made from quartz with an inner diameter of $7 \mathrm{~mm}$. The catalyst zone in the reactor center had a length of $6 \mathrm{~cm}$ and was filled with $0.5 \mathrm{~g}\left(2.3 \mathrm{~cm}^{3}\right)$ of Mo/MCM-22 catalyst. Thermocouples were installed at the inlet of the reactor and in the center of catalyst bed for temperature control. Heating zones at the inlet and the outlet of the reactor were filled with inert particles $\left(\alpha-\mathrm{Al}_{2} \mathrm{O}_{3}\right)$ and glass wool. Gas samples were taken via sample capillaries from two different positions of the fixed-bed reactor: at the reactor inlet and directly after the catalyst bed to measure the product composition. All gas samples were analyzed with an on-line GC-TCD/MSD (Agilent $6890 \mathrm{GC} / 5973 \mathrm{MSD}$ ) system equipped with a three column configuration with several valves as shown in Figure 5. The experiments were performed at atmospheric pressure. A feed dilution for varying the inlet concentration was done by $\mathrm{N}_{2}$ with different percentages. The pressure drop over the catalyst bed was always less than 0.3 bar. Every set of experimental parameters was held for approximately $1.8 \mathrm{~h}$ to reach steady state conditions and last for around $24 \mathrm{~h}$ to get adequate data for steady state and deactivation state as discussed in Figure 3. The same set-up was used for mass transfer measurements for hydrogen selective membranes (see below).

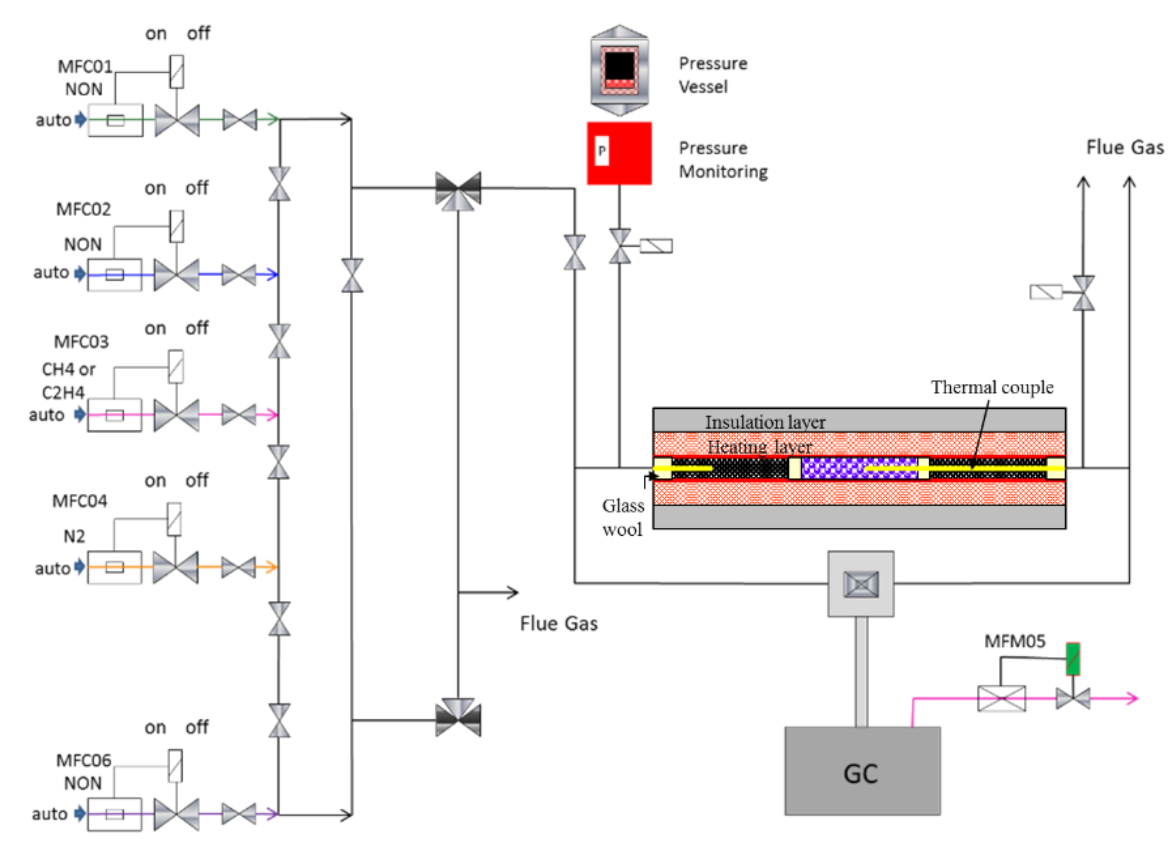

Figure 5: Flow sheet of the experimental set-up for kinetic measurements 


\section{Experimental procedure}

Due to the activation and deactivation phenomena of the Mo/MCM-22 catalyst (Figure 3) two types of experiments were carried out: 1). Single experiments (in every experiment fresh catalyst was used after pretreatment) applying control variable method (change one variable only). 2). Step-wise experiments (catalyst loaded and activated is used accepting gradual deactivation). In order to investigate the influence of different operation parameters, the experiments were classified into 3 sets as listed in Table 1 Furthermore, kinetic experiments with ethylene feed were performed to investigate individually sub-networks.

Table 1: Parameter range of performed kinetic experiments for Mo/MCM-22

\begin{tabular}{ccc}
\hline Set & Range & Indicator \\
\hline Temperature variation & $650-7500^{\circ} \mathrm{C}$ & Groups A, C and E \\
Feed $\mathrm{CH}_{4}$ fraction variation & $30-90 \%$ & Groups B and D \\
$\mathrm{W} / \mathrm{F}$ variation & $720-2160 \mathrm{kgs} / \mathrm{m}^{3}$ & Groups F, G, H and I \\
\hline
\end{tabular}

\section{$\underline{\text { Kinetic investigations }}$}

In order to investigate the conversion and selectivity dependency ontemperature, residence time and feed volume fraction the experiments according to the matrix illustrated in Figure 6 were realized. Each dot corresponds to one experiment and each line stands for one group of experiment. A key result of the experimental observation is the fact, that no clear steady state could be achieved as described in the schematic scheme given in Figure 3. Typical trends observed are illustrated in Figure 7 for four different temperatures observed in runs of group $\mathrm{A}\left(x^{0}{ }_{\mathrm{CH}_{4}}=90 \%, \mathrm{~W} / \mathrm{F}=\right.$ $\left.2160 \mathrm{kgs} / \mathrm{m}^{3}\right)$.

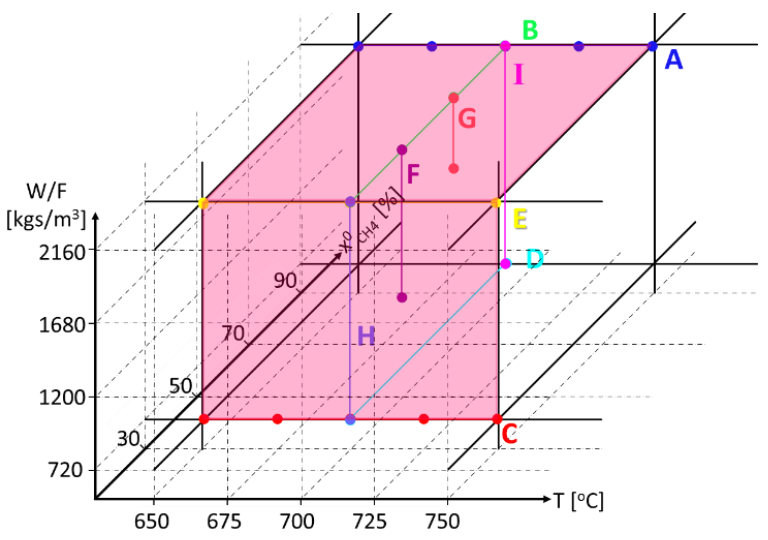

Figure 6: Experimental matrix

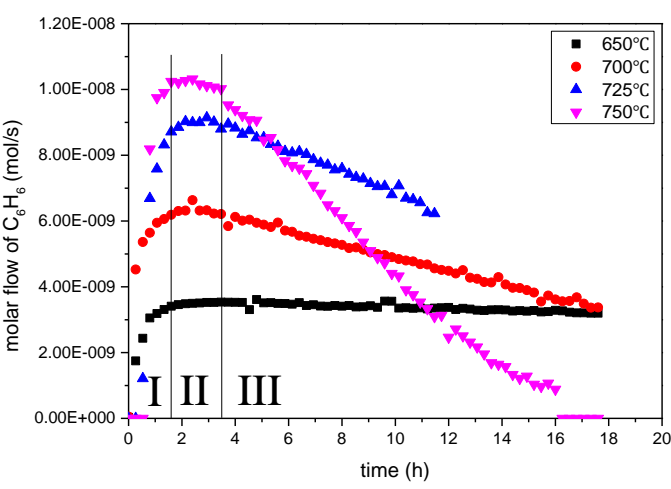

Figure 7: Benzene molar flows vs. reaction time for $x^{0}{ }_{\mathrm{CH}_{4}}=90, \mathrm{~W} / \mathrm{F}=2160 \mathrm{kgs} / \mathrm{m}^{3}$

The process courses are characterized by an induction phase (I), in which Mo carbide was formed, a pseudo steady state phase of a few hours (II) and deactivation phase(III) depending on the reaction temperature set. The performance parameters used for discussion and the kinetic modeling were extracted from averaged concentrations recorded during the pseudo steady state phases. Below we discuss a few instructive trends. More details and results can be found in ${ }^{[18]}$. 
To evaluate the temperature dependency, both single experiments and stepwise experiments were carried out. Most reported MDA reaction temperature is $700^{\circ} \mathrm{C}$. Thus, experiments to evaluate the influence of temperature on MDA performance were carried out at temperatures of $650^{\circ} \mathrm{C}, 675^{\circ} \mathrm{C}$, $725^{\circ} \mathrm{Cand} 750^{\circ} \mathrm{C}$.In the following only the results of Group A $\left(x^{0}{ }_{C H_{4}}=90 \%, W / F=\right.$ $2160 \mathrm{kgs} / \mathrm{m}^{3}$ ) were selected to show the tendency of temperature influence.

Figure 8 shows the methane conversion, the selectivity of benzene as well as the selectivity of the intermediate ethylene and the side product ethane at different temperatures. Obviously, methane conversion is thermodynamically limited and decreases with reaction time caused by catalyst deactivation at all reaction temperatures. For $650^{\circ} \mathrm{C}$ and $700^{\circ} \mathrm{C}$ the methane conversion is almost constant which means Mo/MCM-22 catalyst has relatively long life time and good tolerance of carbonaceous deposits at $700^{\circ} \mathrm{C}$. For temperatures higher than $700^{\circ} \mathrm{C}$, the methane conversion decreases significantly in deactivation stage. This is caused by the deactivation of the catalyst due to the intensified carbon deposit at higher temperatures. Benzene selectivity (Figure 8b) offers analogues tendencies characterized by a sharply increase during the induction period. The maximal benzene selectivity of $10 \%$ at $650^{\circ} \mathrm{C}$ corresponding to conversion of $3 \%$ provides low benzene yields in the conventional fixed-bed reactor used only.
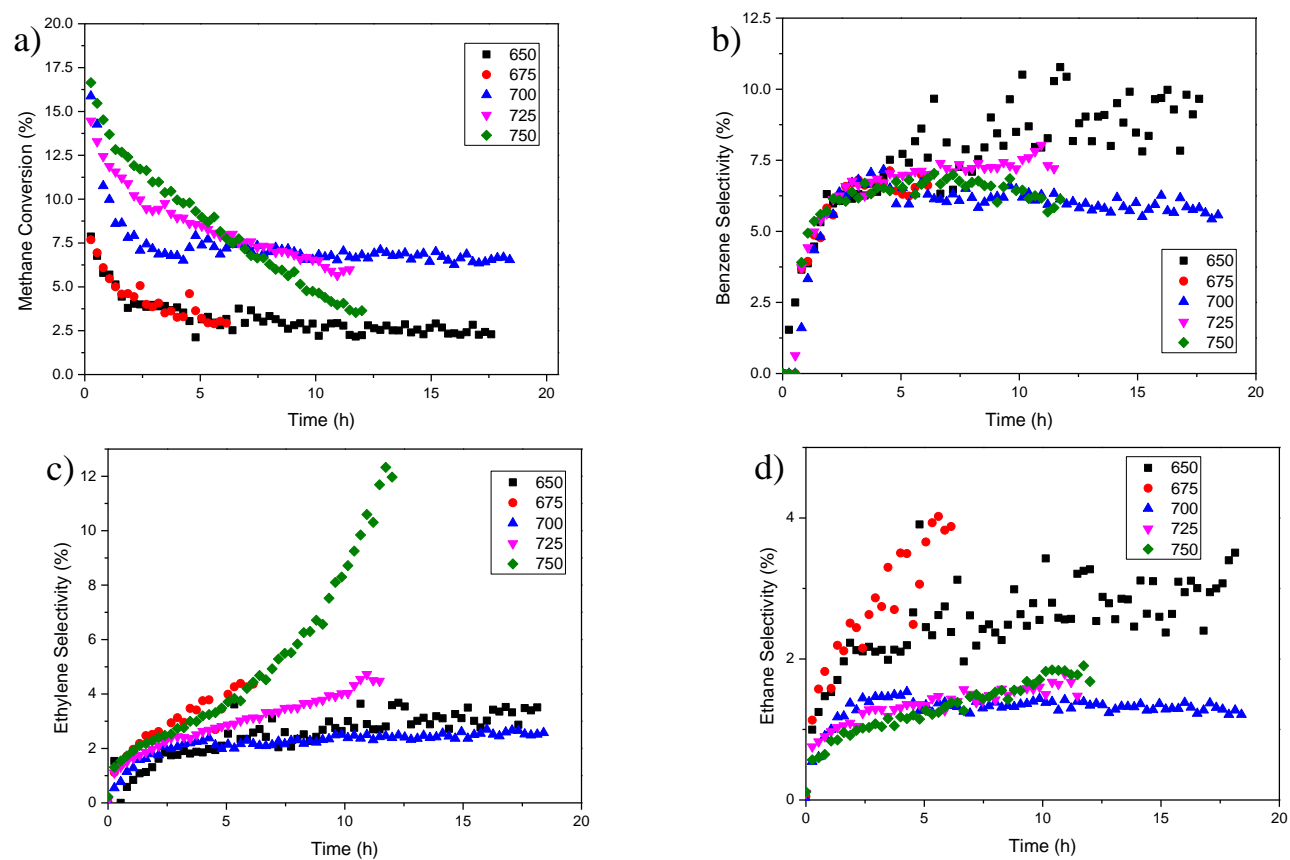

Figure 8: a) methane conversion, b) selectivity of benzene, c) ethylene and d) ethane, single experiment at different temperatures, Group $\mathrm{A}\left(x^{0}{ }_{\mathrm{CH}_{4}}=90 \%, \mathrm{~W} / \mathrm{F}=2160 \mathrm{kgs} / \mathrm{m}^{3}\right)$

A similar behavior of ethylene selectivity was observed for $650^{\circ} \mathrm{C}$ and $700^{\circ} \mathrm{C}$. Ethylene selectivity is increase in induction period and reaches no steady state for the conditions applied. At a temperature of $750^{\circ} \mathrm{C}$, ethylene selectivity is enhanced drastically after four hours corresponding to a lower conversion. Here the catalyst state and the reaction mechanism seem to be changed. The undesired side product ethane can be detected immediately after the reaction starts. Obviously, the intermediate ethylene is hydrogenated due to free hydrogen from cracking reactions. No difference exists between $700^{\circ} \mathrm{C}, 725^{\circ} \mathrm{C}$ and $750^{\circ} \mathrm{C}$. The highest ethane selectivity is at 650 and 675 . Thus the mechanism forming side reactions is changing in this temperature range. 
Results of experiments with stepwise increase in temperature are illustrated in Figure 9. Higher temperatures result in higher methane conversion and faster catalyst deactivation which is included now in every following step. After the induction period (see Fig. 3 and 7), benzene selectivity slightly decreases with increasing temperature, which corresponds to the results of single experiment results. But ethylene selectivity shows somehow different. The ethylene selectivity decreases slightly from $650^{\circ} \mathrm{C}$ to $700^{\circ} \mathrm{C}$ and stays constant on a higher level than the single experiments for a significant higher methane conversion. Consequently a higher benzene yield can be obtained.
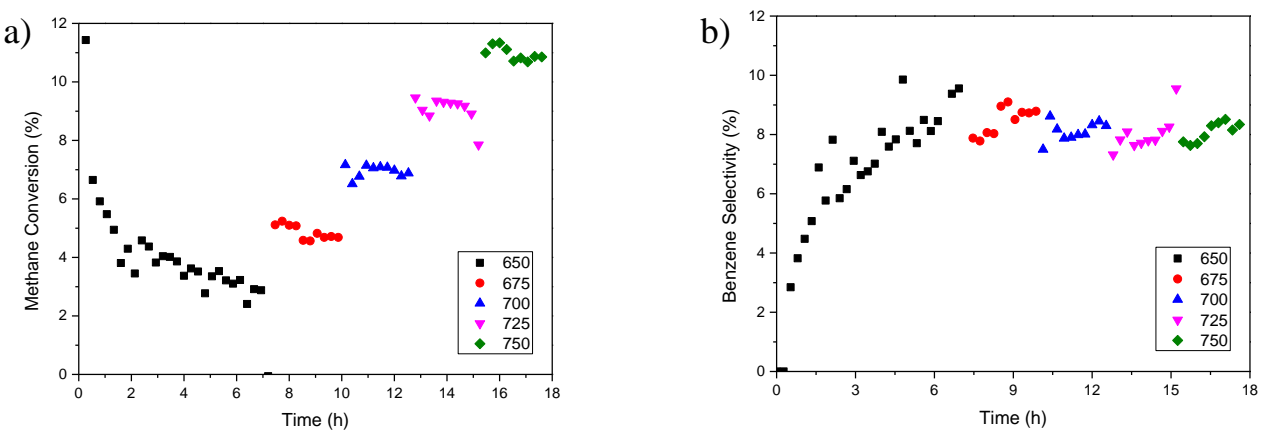

Figure 9: a) methane conversion, b) selectivity of benzene for stepwise experiment at different temperatures, Group A $\left(x^{0}{ }_{C H_{4}}=90 \%, W / F=2160 \mathrm{kgs} / \mathrm{m}^{3}\right)$

The average methane conversion and benzene selectivity at pseudo steady state (II) of single and stepwise experiment are plotted in Figure 10, from which absolute values can be easily compared. Methane conversion of single experiment is lower in the temperature range of $650^{\circ} \mathrm{C}$ to $725^{\circ} \mathrm{C}$ than stepwise experiment. Only at $750^{\circ} \mathrm{C}$ methane conversion is higher than stepwise one, which is because the single experiment used fresh catalyst. The catalyst is already deactivated partially. Benzene selectivity at all temperature of single experiment is lower than in stepwise experiment, but with different extent. This implies that catalyst with carbon deposit favors more benzene production, since molybdenum carbide is the active center of benzene formation. The experimental study of the influence of methane feed concentration (Group B) revealed a decrease of methane conversion with increasing inlet volumetric fraction. The behavior of benzene selectivity tendencies is similar ${ }^{[19]}$.

The selectivity-conversion behavior of results of experiments belonging to Group A, C and E are plotted in Figure 11. From the illustration can be recognized that Group A has relative high benzene selectivity but low methane conversion. While experimental Group E provides a high methane conversion but low benzene selectivity.

In summary, methane conversion and benzene selectivity achieved with the Mo/MCM-22 are still low.

The space time yield of hydrogen produced is around $0.02 \mathrm{~mol} /\left(\mathrm{s} \cdot \mathrm{m}^{3}\right)$. 


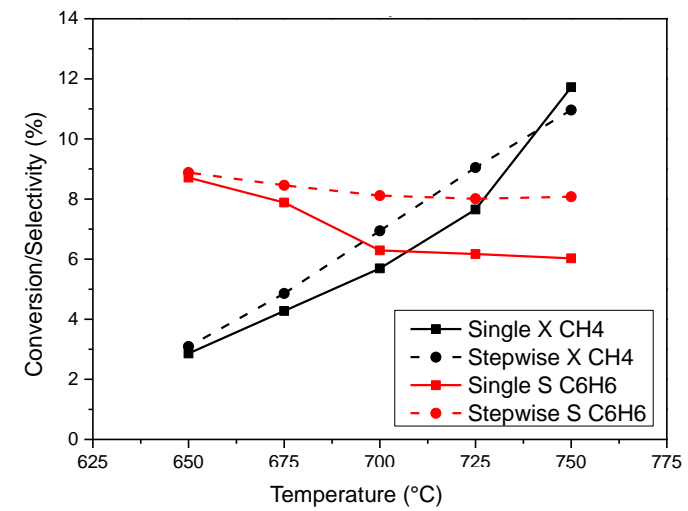

Figure 10: Comparison of methane conversion and benzene selectivity for single and stepwise experiments, Group A

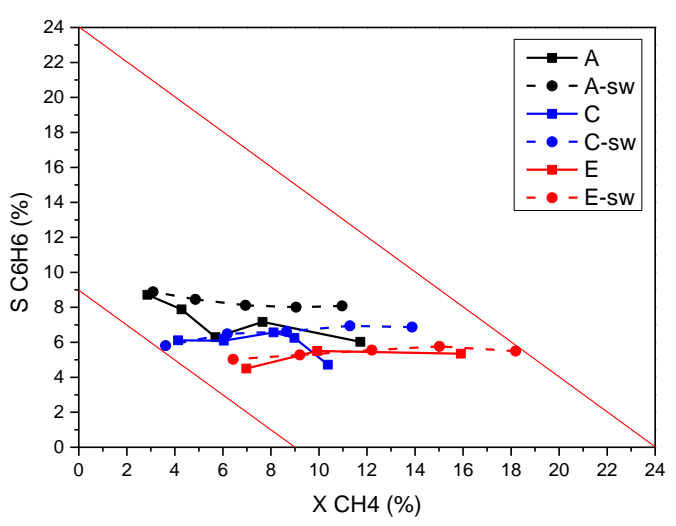

Figure 11: Selectivity- conversion behavior of Group A, C and E

\section{Kinetic model}

A conventional approach to the quantification of reaction rates is to measure reactant or product concentrations as functions of time in a batch reactor or at inlet and outlet of a FBR, respectively. To verify the reaction rate constants quantified from measured results, the kinetic experiments were performed in a tubular quartz reactor for steady state conditions as described above. A simplified reaction network (Figure 2) for MDA was proposed. The thermodynamically limited MDS was described kinetically by applying simple power law approaches (eqs. 2-7) including the corresponding backward reactions. All the parameters for the reversible reaction mechanism estimated are summarized in Table 2. The equilibrium constants $\mathrm{Kp}$ were calculated from the temperature dependent free Gibbs enthalpies ${ }^{[7 c, 15]}$

The equations (2-7) and parameters in Table 2 allow estimating performance parameters of fixed-bed and membrane reactors. In particular the hydrogen production rate and estimated space time yield of hydrogen (STY, STY $\mathrm{H}_{2}=\dot{\mathrm{n}}_{\mathrm{H}_{2}}^{\mathrm{R}} / \mathrm{V}_{\mathrm{R}}$ ) was of further interest and calculated for the catalyst used with approximately $0.021 \mathrm{~mol} /(\mathrm{s} \cdot \mathrm{m} 3)$. This amount of hydrogen has to be removed selectively in a membrane extractor to overcome the limitation by chemical equilibrium as shown in Figure 1. Thus, to evaluate the compatibility of reaction and mass transfer rules, the membrane is characterized in the next chapter.

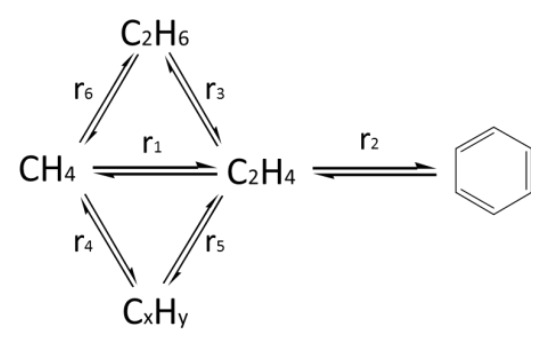

Figure 2: Illustration of simplified reaction network

$$
\begin{aligned}
& 2 \mathrm{CH}_{4} \leftrightarrow \mathrm{C}_{2} \mathrm{H}_{4}+2 \mathrm{H}_{2} \quad \mathrm{r}_{1}=\mathrm{k}_{1} \mathrm{C}_{\mathrm{CH}_{4}}{ }^{\alpha_{1}} \cdot\left(1-\frac{\mathrm{C}_{\mathrm{C}_{2} \mathrm{H}_{4}} \cdot \mathrm{C}_{\mathrm{H}_{2}}^{2}}{\mathrm{C}_{\mathrm{CH}_{4}}^{2}} \cdot \frac{1}{\mathrm{Kp}_{1}}\right) \\
& 3 \mathrm{C}_{2} \mathrm{H}_{4} \leftrightarrow \mathrm{C}_{6} \mathrm{H}_{6}+3 \mathrm{H}_{2} \quad \mathrm{r}_{2}=\mathrm{k}_{2} \mathrm{C}_{\mathrm{C}_{2} \mathrm{H}_{4}} \alpha_{2} \cdot\left(1-\frac{\mathrm{C}_{\mathrm{C}_{6} \mathrm{H}_{6}} \cdot \mathrm{C}_{\mathrm{H}_{2}}^{3}}{\mathrm{C}_{\mathrm{C}_{2} \mathrm{H}_{4}}^{3}} \cdot \frac{1}{\mathrm{Kp}_{2}}\right) \\
& \mathrm{C}_{2} \mathrm{H}_{4}+\mathrm{H}_{2} \leftrightarrow \mathrm{C}_{2} \mathrm{H}_{6} \quad \mathrm{r}_{3}=\mathrm{k}_{3} \mathrm{C}_{\mathrm{C}_{2} \mathrm{H}_{4}} \alpha_{3} \cdot\left(1-\frac{\mathrm{C}_{\mathrm{C}_{2} \mathrm{H}_{6}}}{\mathrm{C}_{\mathrm{C}_{2} \mathrm{H}_{4}} \cdot \mathrm{C}_{\mathrm{H}_{2}}} \cdot \frac{1}{\mathrm{Kp}_{3}}\right) \\
& \mathrm{xCH}_{4} \leftrightarrow \mathrm{C}_{\mathrm{x}} \mathrm{H}_{\mathrm{y}}+\frac{4 \mathrm{x}-\mathrm{y}}{2} \mathrm{H}_{2} \quad \mathrm{r}_{4}=\mathrm{k}_{4} \mathrm{C}_{\mathrm{CH}_{4}}{ }^{\alpha_{4}} \cdot\left(1-\frac{\mathrm{C}_{\mathrm{C}} \mathrm{H}_{\mathrm{y}} \cdot \mathrm{C}_{\mathrm{H}_{2}}}{\mathrm{C}_{\mathrm{CH}_{4}}} \cdot \frac{1}{\mathrm{Kp}_{4}}\right) \\
& \mathrm{xC}_{2} \mathrm{H}_{4} \leftrightarrow 2 \mathrm{C}_{\mathrm{x}} \mathrm{H}_{\mathrm{y}}+(2 \mathrm{x}-\mathrm{y}) \mathrm{H}_{2} \quad \mathrm{r}_{5}=\mathrm{k}_{5} \mathrm{C}_{\mathrm{C}_{2} \mathrm{H}_{4}}{ }^{\alpha_{5}} \cdot\left(1-\frac{\mathrm{C}_{\mathrm{C}_{\mathrm{x}} \mathrm{H}_{\mathrm{y}}}^{2} \mathrm{C}_{\mathrm{H}_{2}}}{\mathrm{C}_{\mathrm{C}_{2} \mathrm{H}_{4}}} \cdot \frac{1}{\mathrm{Kp}_{5}}\right)
\end{aligned}
$$

$$
2 \mathrm{CH}_{4} \leftrightarrow \mathrm{C}_{2} \mathrm{H}_{6}+\mathrm{H}_{2} \quad \mathrm{r}_{6}=\mathrm{k}_{6} \mathrm{C}_{\mathrm{CH}_{4}}{ }^{\alpha_{6}} \cdot\left(1-\frac{\mathrm{C}_{\mathrm{C}_{2} \mathrm{H}_{6}} \cdot \mathrm{C}_{\mathrm{H}_{2}}}{\mathrm{C}_{\mathrm{CH}_{4}}^{2}} \cdot \frac{1}{\mathrm{Kp}_{6}}\right)
$$


Table 2: Estimates kinetic parameters for MDA on a Mo/MCM-22 catalyst

\begin{tabular}{cccc}
\hline \multirow{2}{*}{ Reaction } & Activation energy & Pre-factor & Reaction order \\
\cline { 2 - 4 } & $\left(\mathrm{E}_{\mathrm{A}} \frac{\mathrm{kJ}}{\mathrm{mol} \cdot \mathrm{K}}\right)$ & $\left(\mathrm{k}_{\infty} \frac{\mathrm{m}^{3 \alpha-3}}{\mathrm{~s} \cdot \mathrm{mol}^{\alpha-1}}\right)$ & $(\alpha)$ \\
\hline $\mathrm{r}_{1}$ & 112.2 & 1147 & 0.86 \\
$\mathrm{r}_{2}$ & 19.1 & 1.55 & 0.94 \\
$\mathrm{r}_{3}$ & 25.7 & 2.16 & 1.24 \\
$\mathrm{r}_{4}$ & 82.2 & 73.68 & 0.57 \\
$\mathrm{r}_{5}$ & 58.3 & 22.78 & 1.00 \\
$\mathrm{r}_{6}$ & 14.7 & $2.8 \mathrm{e}-4$ & 1.02 \\
\hline
\end{tabular}

\section{Hydrogen selective membrane}

As reported above, methane conversion and benzene selectivity achieved with the Mo/MCM-22 are still low. The space time yield of hydrogen produced was found to be around $0.021 \mathrm{~mol} /\left(\mathrm{s} \cdot \mathrm{m}^{3}\right)$.

Membrane reactors (MR) ${ }^{[20]}$ can eventually be promising to overcome the thermodynamic limitation of MDA and to increase methane conversion and benzene yield. For this membranes with compatible hydrogen permeability are needed.

The hydrogen selective carbon membrane used in this work was prepared by Fraunhofer Institute for Keramische Technologien und Systeme (IKTS) Hermsdorf. The membrane was a thin layer of carbon deposed on a porous alumina oxide support. The support itself was a multilayered porous material of tubular geometry $(\mathrm{OD}=10 \mathrm{~mm}, \mathrm{ID}=7 \mathrm{~mm})$. The hydrogen permeability of a fresh carbon membrane was measured by single, binary and ternary gas permeation tests at different temperatures and pressures. The mass transport quantification of single gas and gas mixtures through the carbon membrane at different temperatures have to be determined in advance.

In order to investigate the permeation flux, single gas permeation at different pressures and temperatures were carried out. A detailed membrane modelling can be performed using Dusty Gas Model ${ }^{[16]}$. In this contribution, a much simple polynomial approach was used because the individual membrane layers were not available individually. The modelling of the used carbon membrane is polynomial of temperature. For $\mathrm{He}, \mathrm{H}_{2}$ and $\mathrm{CH}_{4}$, the diffusion flux as a function of pressure difference is:

$J=-\left(A \cdot T^{2}+B \cdot T+C\right) \cdot \Delta p$

While for $\mathrm{N}_{2}$ permeation, the diffusion flux can be calculated as:

$J=-\left(\frac{1}{D \cdot T^{2}+E \cdot T+F}\right) \cdot \Delta p$

The diffusion parameters in the above two equations were estimated and the results are shown in Table 3. 
Table 3: Diffusivities parameters for carbon membrane

\begin{tabular}{ccccccc}
\hline $\mathrm{Gas}$ & $\begin{array}{c}\mathrm{A} \\
\left(\mathrm{mol} /\left(\mathrm{sm}^{2} \mathrm{PaK}^{2}\right)\right)\end{array}$ & $\begin{array}{c}\mathrm{B} \\
\left(\mathrm{mol} /\left(\mathrm{sm}^{2} \mathrm{PaK}^{2}\right)\right)\end{array}$ & $\begin{array}{c}\mathrm{C} \\
\left(\mathrm{mol} /\left(\mathrm{sm}^{2} \mathrm{PaK}^{2}\right)\right)\end{array}$ & $\begin{array}{c}\mathrm{D} \\
\left(\left(\mathrm{sm}^{2} \mathrm{PaK}^{2}\right) / \mathrm{mol}\right)\end{array}$ & $\begin{array}{c}\mathrm{E} \\
\left(\left(\mathrm{sm}^{2} \mathrm{PaK}^{2}\right) / \mathrm{mol}\right)\end{array}$ & $\begin{array}{c}\mathrm{F} \\
\left(\left(\mathrm{sm}^{2} \mathrm{PaK}^{2}\right) / \mathrm{mol}^{2}\right.\end{array}$ \\
\hline $\mathrm{CH}_{4}$ & $-9.06 \mathrm{E}-14$ & $1.37 \mathrm{E}-10$ & $-5.79 \mathrm{E}-09$ & & & \\
$\mathrm{He}$ & $-9.18 \mathrm{E}-14$ & $4.70 \mathrm{E}-10$ & $1.28 \mathrm{E}-07$ & & & \\
$\mathrm{~N}_{2}$ & & & & $-6.77 \mathrm{E}+01$ & $9.12 \mathrm{E}+04$ & $-6.18 \mathrm{E}+06$ \\
$\mathrm{H}_{2}$ & $-7.60 \mathrm{E}-13$ & $1.78 \mathrm{E}-9$ & $-2.95 \mathrm{E}-07$ & & & \\
\hline
\end{tabular}

Based on the parameters above, it can be estimated that at $\mathrm{T}=700^{\circ} \mathrm{C}$ the hydrogen area time yield (ATY, $A T Y=\dot{n}_{H_{2}}^{M} / A_{M}$ ) of this carbon membrane is $0.018 \mathrm{~mol} /\left(\mathrm{s} \cdot \mathrm{m}^{2}\right)$. The space time yield of hydrogen is $0.021 \mathrm{~mol} /\left(\mathrm{s} \cdot \mathrm{m}^{3}\right)$ also for product benzene $S T Y_{C_{6} H_{6}}$ is approximately $0.0017 \mathrm{~mol} /\left(\mathrm{s} \cdot \mathrm{m}^{3}\right)$, which is below the typical "window of reality" of STY=1-10 $\mathrm{mol} /\left(\mathrm{s} \cdot \mathrm{m}^{3}\right)$ for the operation of catalytic reactors operated in industry ${ }^{[17]}$. To match the hydrogen fluxes of reaction and separation ("kinetic compatibility" ${ }^{[17]}$ ), the required ratios of membrane area to reactor volume $\left(A_{M} /\right.$ $V_{R}$ for $\left.\dot{n}_{H_{2}}^{M} / \dot{n}_{H_{2}}^{R}=1\right)$ is $1.18 \mathrm{~m}^{-1}[17]$. These relative low values indicate that an accommodation of a sufficiently large membrane area in a considered reactor volume is easily feasible (see Figure 12). In van de Graaf ${ }^{[17]}$ examples are given that $A_{M} / V_{R}$ ratios of up to 100 can be nowadays realized in membrane reactors.

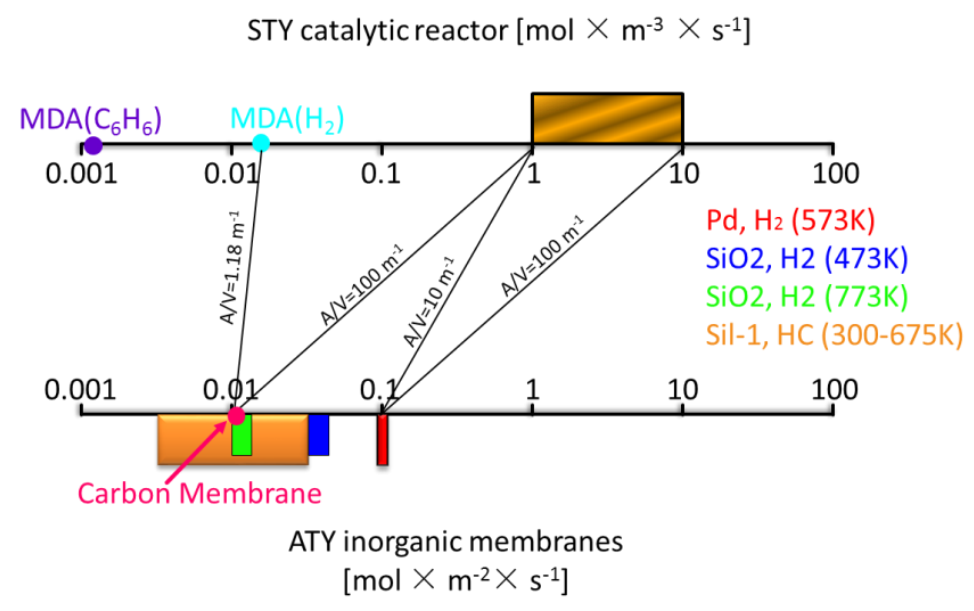

Figure 12: Comparison of the space time yield (STY) of typical large scale catalytic reactors (box) with area time yield (ATY) of several inorganic membranes ${ }^{[17]}$

To evaluate the effect of the characterized membrane, the performance of a membrane reactor in extractor configuration for MDA reaction was studied via simulations using the estimated reaction kinetics (eq. 2-7) with parameters in Table 2 and the characterized carbon membrane with parameters in Table 3. Therefore a reduced, isothermal 1-D membrane and fixed-bed reactor model was applied ${ }^{[20-21]}$. The calculated results reveal for the "carbon MR" a 23\% higher benzene yield in comparison to the conventional fixed-bed reactor (FBR) by removing hydrogen selectively via membranes. Nevertheless, for the application of membrane reactors in MDA, a better membrane with higher hydrogen selectivity, hydrogen transfer rate and stability is needed. 


\section{Conclusion}

The potential of a Mo/MCM-22 catalyst for MDA in a FBR was studied experimentally and theoretically. In the experiments no real steady state was achieve. A pseudo steady state phase was defined to quantify the results. With increasing temperature, the pseudo steady state and methane conversion increased but benzene selectivity decreased. A simplified reaction network was proposed and all the parameters in a reversible kinetic model were estimated. The results of this paper provide for further work a performance map and guidelines how temperature, feed concentration and residence time influence the MDA performance. The results reveal that the MDA performance achieved in this work is still rather small for industry application. The stability of the catalyst investigated is better than published literature but still not good enough for industrial application. A hydrogen selective carbon membrane was characterized experimentally and mathematically regarding its potential in a membrane reactor. For further investigation of the non oxidative MDA, better catalyst and suitable membranes need to be developed.

Finally should be mentioned, that more recently also promising catalysts were reported which give "hope". Guo ${ }^{[22]}$ developed a $0.5 \% \mathrm{FeSiO}_{2}$ catalyst with single iron sites embedded in a silica matrix for direct non oxidative methane conversion. $48.1 \%$ methane conversion was obtained at $1090{ }^{\circ} \mathrm{C}$ and $21.4 \mathrm{l} /(\mathrm{gh})$ space velocity in a micro reactor with a selectivity to ethylene of $>48.4 \%$ and to aromatic of $>47.3 \%$. Moreover, no deactivation was observed even after $60 \mathrm{~h}$ on stream and the total selectivity (to $\mathrm{C}_{2} \mathrm{H}_{4}, \mathrm{C}_{6} \mathrm{H}_{6}$ and $\mathrm{C}_{7} \mathrm{H}_{8}$ ) remained $>99 \%$.

\section{Acknowledgement:}

The financial support of Deutsche Forschungsgemeinschaft (SFB-TR 63 "Integrated chemical processes in multi-phase fluid systems") and the Chinese Scholarship Council for establishing and financing this German-Chinese Cooperation project is gratefully acknowledged.

We are very grateful to Dr. Hannes Richter and Dr. Ingolf Voigt from Fraunhofer Institute for Keramische Technologien und Systeme (IKTS) Hermsdorf for the supply of membranes. 


\section{$\underline{\text { References }}$}

[1] K. S. Wong, J. W. Thybaut, E. Tangstad, M. W. Stöcker, G. B. Marin, Microporous and Mesoporous Materials 2012, 164, 302-312.

[2] A. Martínez, E. Peris, G. Sastre, Catalysis Today 2005, 107-108, 676-684.

[3] S. Ma, X. Guo, L. Zhao, S. Scott, X. Bao, Journal of Energy Chemistry 2013, 22, 1-20.

[4] B. F. A. Abasov S J, Dadashev B A, Kinet Catal 1991, 32, 202-205.

[5] a) Z. R. Ismagilov, E. V. Matus, L. T. Tsikoza, Energy \& Environmental Science 2008, 1, 526; b) E. V. Matus, I. Z. Ismagilov, O. B. Sukhova, V. I. Zaikovskii, L. T. Tsikoza, Z. R. Ismagilov, J. A. Moulijn, Industrial \& Engineering Chemistry Research 2006, 46, 4063-4074; c) Y. Shu, R. Ohnishi, M. Ichikawa, Journal of Catalysis 2002, 206, 134-142; d) D. Zhou, D. Ma, X. Liu, X. Bao, Journal of Molecular Catalysis A: Chemical 2001, 168, 225-232; e) D. Ma, Y. Shu, X. Bao, Y. Xu, Journal of Catalysis 2000, 189, 314-325; f) S. Liu, L. Wang, R. Ohnishi, M. Ichikawa, Journal of Catalysis 1999, 181, 175-188; g) H. Jiang, L. Wang, W. Cui, Y. Xu, Catalysis Letters 1999, 57, 95-102; h) W. Zhang, D. Ma, X. Han, X. Liu, X. Bao, X. Guo, X. Wang, Journal of Catalysis 1999, 188, 393-402; i) B. M. Weckhuysen, D. Wang, M. P. Rosynek, J. H. Lunsford, Journal of Catalysis 1998, 175, 338-346.

[6] aD. Y. Wang, Q. B. Kan, N. Xu, P. Wu, T. H. Wu, Catalysis Today 2004, 93-95, 75-80; b) S. Yao, C. Sun, J. Li, X. Huang, W. Shen, Journal of Natural Gas Chemistry 2010, 19, 1-5; cC. Sun, S. Yao, W. Shen, L. Lin, Microporous and Mesoporous Materials 2009, 122, 48-54.

[7] a)D. Ma, F. Deng, R. Fu, X. Han, X. Bao, The Journal of Physical Chemistry B 2001, 105, 1770-1779; b) N. Chu, J. Wang, Y. Zhang, J. Yang, J. Lu, D. Yin, Chemistry of Materials 2010, 22, 2757-2763; c) N. Chu, J. Yang, J. Wang, S. Yu, J. Lu, Y. Zhang, D. Yin, Catalysis Communications 2010, 11, 513-517; d) Z. Sobalík, Z. Tvarůžková, B. Wichterlová, V. Fíla, Š. Špatenka, Applied Catalysis A: General 2003, 253, 271-282; e) D. Ma, Journal of Catalysis 2002, 208, 260-269; f) V. T. T. Ha, L. V. Tiep, P. Meriaudeau, C. Naccache, Journal of Molecular Catalysis A: Chemical 2002, 181, 283-290; g) H. Liu, L. Su, H. Wang, W. Shen, X. Bao, Y. Xu, Applied Catalysis A: General 2002, 236, 263-280; h) D. Ma, Y. Shu, X. Han, X. Liu, Y. Xu, X. Bao, The Journal of Physical Chemistry B 2001, 105, 1786-1793.

[8] W. Ding, S. Li, G. D Meitzner, E. Iglesia, The Journal of Physical Chemistry B 2000, 105, 506-513.

[9] H. Liu, X. Bao, Y. Xu, Journal of Catalysis 2006, 239, 441-450.

[10] Y. Xu, Y. Shu, S. Liu, J. Huang, X. Guo, Catalysis Letters 1995, 35, 233-243.

[11] L. Wang, L. Tao, M. Xie, G. Xu, J. Huang, Y. Xu, Catalysis Letters 1993, 21, 35-41.

[12] a) L. Su, L. Liu, J. Zhuang, H. Wang, Y. Li, W. Shen, Y. Xu, X. Bao, Catalysis Letters 2003, 91, 155-167; b) B. S. Liu, Y. Zhang, J. F. Liu, M. Tian, F. M. Zhang, C. T. Au, A. S. C. Cheung, The Journal of Physical Chemistry C 2011, 115, 16954-16962; c) L. Wang, R. Ohnishi, M. Ichikawa, Journal of Catalysis 2000, 190, 276-283; d) S. Li, C. L. Zhang, Q. B. Kan, D. Y. Wang, T. H. Wu, L. W. Lin, Appl Catal a-Gen 1999, 187, 199-206; e) D. Ma, Y. Shu, C. Zhang, W. Zhang, X. Han, Y. Xu, X. Bao, Journal of Molecular Catalysis A: Chemical 2001, 168, 139-146; f) J.-F. Liu, L. Jin, Y. Liu, Y.-S. Qi, Catalysis Letters 2008, 125, 352-358; g) P. L. Tan, C. T. Au, S. Y. Lai, Catal Lett 2006, 112, 239-245.

[13] S.-T. Wong, Y. Xu, W. Liu, L. Wang, X. Guo, Applied Catalysis A: General 1996, 136, 7-17.

[14] Y. Shu, D. Ma, L. Xu, Y. Xu, X. Bao, Catalysis Letters 2000, 70, 67-73. 
[15] a) D. Wang, J. H. Lunsford, M. P. Rosynek, Journal of Catalysis 1997, 169, 347-358; b) D. Wang, J. Lunsford, M. Rosynek, Topics in Catalysis 1996, 3, 289-297; c) B. Weckhuysen, M. Rosynek, J. Lunsford, Catalysis Letters 1998, 52, 31-36.

[16] A. P. M. E. A. Mason, Gas Transport in Porous Media: The Dusty Gas Model, Elsevier, Amsterdam-Oxford-New York, 1983.

[17] J. M. van de Graaf, M. Zwiep, F. Kapteijn, J. A. Moulijn, Applied Catalysis A: General 1999, $178,225-241$.

[18] K. Gao, Methane Dehydro-Aromatization kinetic romatization investigation and potential of membrane reactor application evaluation, Ph.D. Thesis, Otto von Guericke Universität Magdeburg, 2015

[19] C. L. Yaws, Chemical Properties Handbook, Mac Graw Hill, ISBN-13: 978-1606235270, 1998

[20] A. Seidel-Morgenstern, Membrane Reactors: Distributing reactants to Improve Selectivity and Yield, Wiley-VCH, ISBN-13: 978-3527320394, 2010

[21] C. Hamel, T. Wolff, S. Pushpavanam, A. Seidel-Morgenstern: Multi-component Dosing in Membrane Reactors Including Recycling - Concept and Demonstration for the Oxidative Dehydrogenation of Propane. Industrial \& Engineering Chemistry Research, 50, 12895-12903, 2011

[22]X. Guo, G. Fang, G. Li, H. Ma, H. Fan, L. Yu, C. Ma, X. Wu, D. Deng, M. Wei, D. Tan, R. Si, S. Zhang, J. Li, L. Sun, Z. Tang, X. Pan, X. Bao, Direct, nonoxidative conversion of methane to ethylene, aromatics, and hydrogen, Science, 344, doi: 10.1126/science.1253150, 2015 